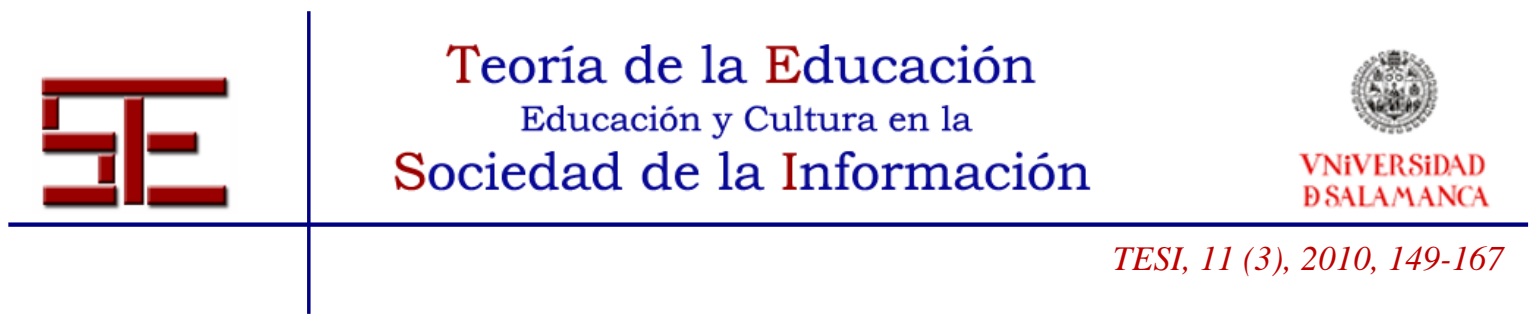

\title{
FUENTES HISTÓRICAS DE LOS JUEGOS DE ROL: UN EXPERIMENTO PARA LA DIDÁCTICA DE LA HISTORIA ANTIGUA
}

Resumen: En este estudio pretendemos resaltar la importancia de las fuentes históricas para la concepción y ambientación de los distintos juegos de rol y, por consiguiente, también la utilidad de éstos para la didáctica de la Historia. Asimismo, planteamos los resultados de un experimento didáctico en el nivel universitario desarrollado con un juego de rol ambientado en la Edad Antigua y más precisamente en época del Imperio Romano.

Palabras clave: Historia; didáctica; juegos de rol; Antigüedad; Imperio Romano.

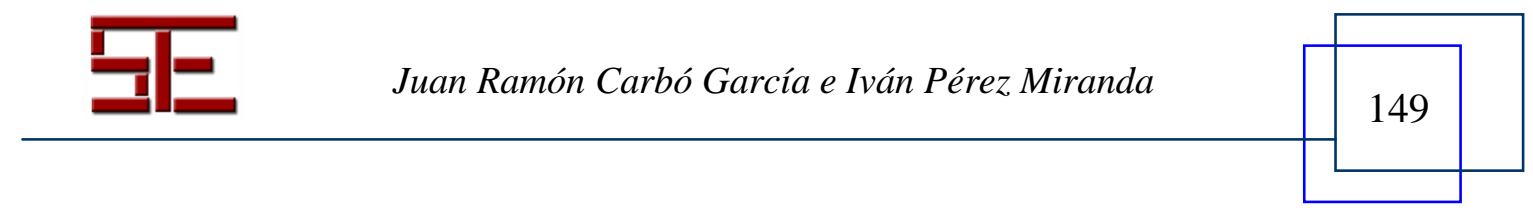




\title{
HISTORICAL SOURCES FOR THE ROL-PLAYING GAMES: AN EXPERIMENT ON THE DIDACTICAL TEACHING OF THE ANCIENT HISTORY
}

\begin{abstract}
On this paper we intend to emphasize the importance of the historical sources for the conception and ambient of different rol-playing games; therefore, the usefulness of these for the didactical teaching of History too. Likewise, we collect the results of a didactic experiment on university level developed with a rol-playing game set in the Ancient Age and more precisely in the times of the Roman Empire.
\end{abstract}

Key words: History; didactical teaching; rol-playing games; Antiquity; Roman Empire.

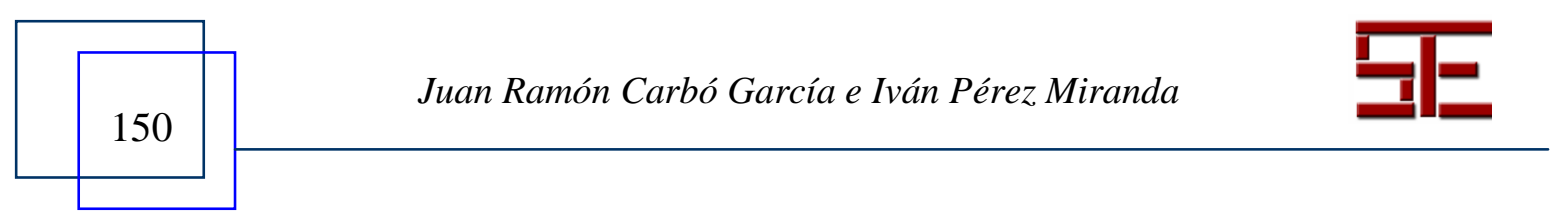




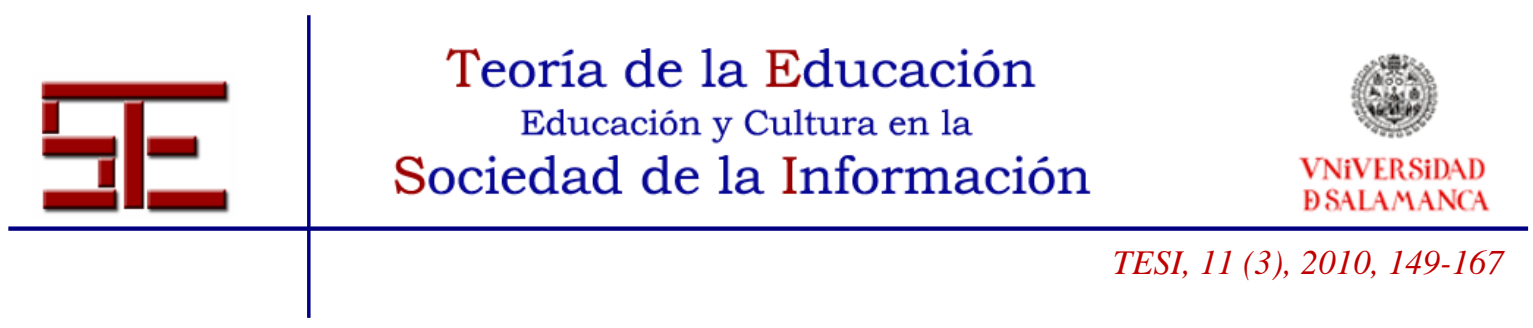

\title{
FUENTES HISTÓRICAS DE LOS JUEGOS DE ROL: UN EXPERIMENTO PARA LA DIDÁCTICA DE LA HISTORIA ANTIGUA
}

\author{
Fecha de recepción: 15/05/2010; fecha de aceptación: 04/10/2010; fecha de publicación: 30/11/2010
}

Juan Ramón Carbó García

siren_de_sorren@hotmail.com

Academia de Rumanía en Roma - Universidad Complutense de Madrid

Iván Pérez Miranda

ivan@usal.es

Universidad de Salamanca

Cuando nos disponemos a hablar de historia y juegos de rol, y de la importancia de la relación existente entre ellos, muchos podrían pensar que lo que pretendemos con esta intervención es plantear una oposición entre historia y fantasía, estableciendo la defensa de la primera y una crítica negativa de la segunda, como tal vez pudiera corresponder sin producir demasiada sorpresa por ello- a un estudio realizado en el medio universitario. Sin embargo, debemos determinar que no es esa nuestra intención y tampoco es nuestro objetivo, que esperamos resultará claramente esbozado en los próximos párrafos.

Todo juego de rol tiene una ambientación, necesaria para su desarrollo, y esa ambientación está basada en algún tipo de fuente, de donde se pueden obtener los datos igualmente necesarios para lograr esbozarla de forma satisfactoria (Sánchez, 2006-2007, 14-15). Pues bien, a lo largo de estas páginas vamos a intentar plantear unas reflexiones sobre las fuentes de índole histórica usadas para los juegos de rol, y no sólo para los de temática histórica, sino también para muchos otros que corresponden al género fantástico. Y es que, como vamos a ver, la historia constituye una fuente esencial para la elaboración fantástica, que se apoya siempre en mayor o menor medida en lo que conocemos, en lo real, en lo existente, en lo pasado, en lo histórico..., para después variarlo en diferente gradación. Pero al mismo tiempo, también existe la fantasía histórica, un término con el que queremos referirnos a la elaboración de fantasías que llegan a formar parte de la historia, como, por ejemplo, sucedería con la mitología al reunir un conjunto de mitos más o menos cohesionados, basados en tradiciones y leyendas y que en gran medida -aunque no todos ellos- fueron creados para explicar el

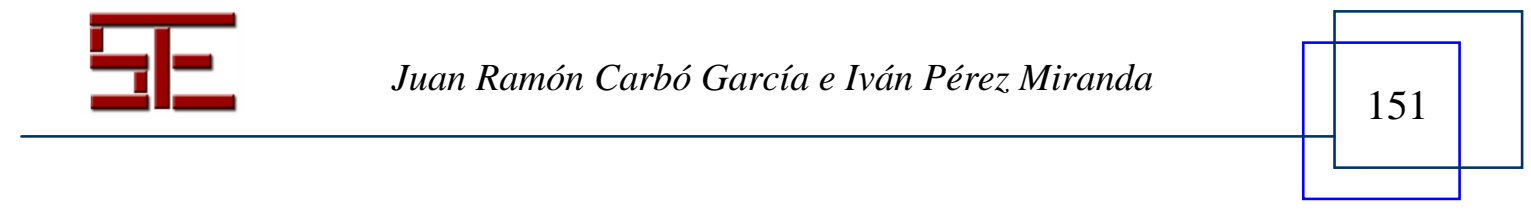




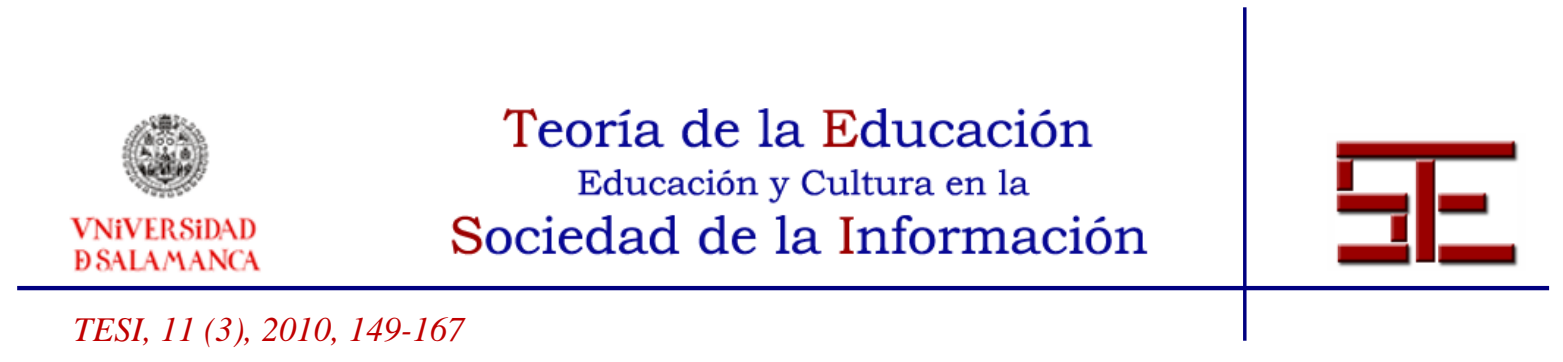

origen del mundo y las fuerzas de la naturaleza, unidos generalmente a unos dioses, a una religión y a una cultura histórica (Vernant, 1991; Scheid, 1991; Sissa; Detienne, 1994). Precisamente, los mitos expresan los puntos de vista y las creencias de un país, una época, una cultura o una religión que constituyeron su origen, y, en este sentido, la mitología constituye en sí misma una fuente histórica de suma importancia para muchos de los juegos de rol de género fantástico.

Las fuentes históricas proporcionan la ambientación necesaria para muchos juegos de rol, contribuyen a la elaboración de la acción o eventos que van a desarrollarse en el juego (pueden ser hechos históricos que se intentan reproducir con mayor o menor fidelidad en el juego de rol, o bien meras fuentes de inspiración para crear un relato, una acción o eventos en otra época histórica en la que se pretende jugar o incluso en un juego de temática fantástica).

Por supuesto, aparte del evidente valor educativo de los juegos de rol en general, un aspecto archiconocido y que ya está siendo y va a ser tratado en otros artículos del presente monográfico, la importancia que las fuentes históricas tienen en ellos (desde su diseño y ambientación hasta el propio desarrollo del juego) hace que podamos resaltar aún más el valor didáctico que tienen estos juegos para la enseñanza y el aprendizaje de la propia historia. No pretendemos encargarnos aquí de presentar un estudio que pueda ilustrar sobre las importantes aplicaciones didácticas que tienen los juegos de rol tanto en Geografía como en Historia, pero sí nos gustaría dedicar al menos una parte de nuestra exposición al papel didáctico que pueden tener los juegos de rol en la Historia Antigua, teniendo en cuenta nuestra especialización, y de ese modo dirigiremos además nuestra atención al nivel de la educación superior universitaria, complementando así en una pequeña parte lo que estudios generales sobre el rol y la didáctica de la Geografía y la Historia puedan plantear. Y pretendemos hacerlo mostrando los resultados de un experimento didáctico con un juego de rol de género histórico ambientado en la Edad Antigua.

Pero dejaremos estos planteamientos y las nuevas perspectivas surgidas de los resultados obtenidos para el final de nuestra exposición, a modo de conclusión de este estudio.

Comentábamos que las fuentes históricas desempeñan un papel muy importante en los juegos de rol, especialmente en lo que a su ambientación se refiere. Somos conscientes de que los defensores de la ambientación fantástica de los juegos de rol podrían poner inmediatamente el grito en el cielo ante una afirmación de semejante calado, argumentando que hay muchísimos más juegos de rol de género fantástico que de género histórico. Y tendrían razón. Hasta ahí, de acuerdo, pero un análisis más profundo

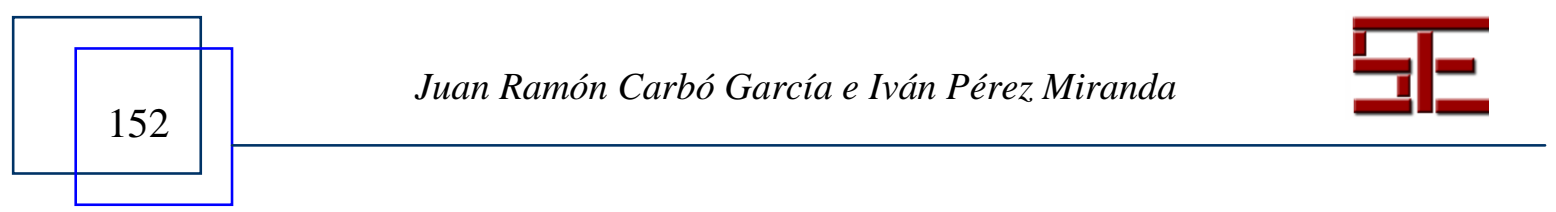




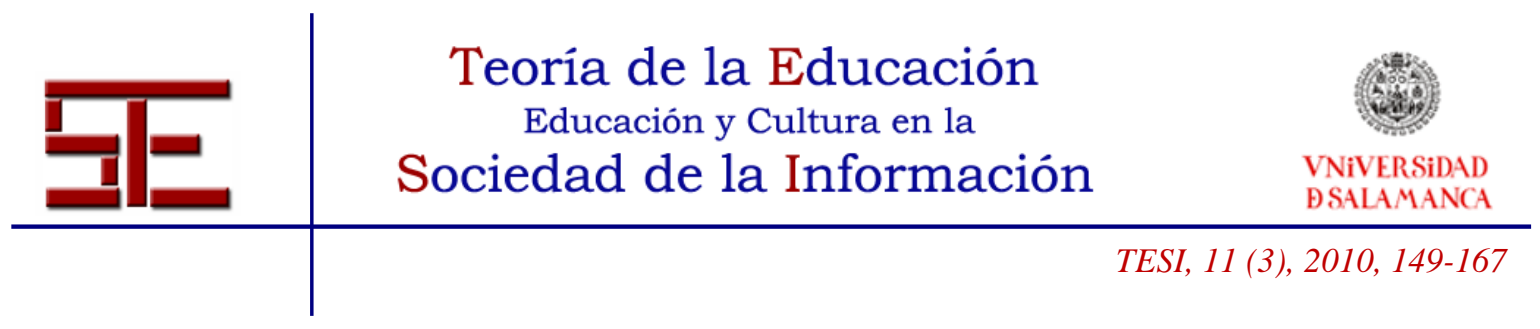

revela que incluso en esos juegos de rol fantásticos las fuentes históricas juegan un rol destacado. En el panorama editorial de los juegos de rol disponemos de juegos de aventuras fantásticas, de ciencia-ficción, de terror fantástico... y también muchos otros juegos de aventuras o de acción histórica, pudiendo cada uno de ellos estar basado o no en novelas (como pasaría con El Señor de los Anillos, de Tolkien; Las aventuras del capitán Alatriste, de Pérez-Reverte, o La llamada de Cthulhu, de Lovecraft), en películas y series de televisión (La Guerra de las Galaxias, Star Trek), en leyendas y mitos populares (los hombres-lobo, los vampiros, etc.), o, más sencillamente, en épocas y ambientes históricos (la época de los piratas, la Segunda Guerra Mundial, la Edad Media, la Edad Antigua...).

¿Y qué encontramos de histórico, por ejemplo, en Dungeons \& Dragons, el juego de rol por excelencia, de ambientación medieval fantástica? Pues su propia descripción lo indica: ambientación medieval. En este caso, la vida cotidiana reflejada en el juego es semejante a la existente en la Edad Media histórica, desde la vida en las ciudades y aldeas a la existencia de caballeros y de castillos y del feudalismo, las formas de vestir y de hablar, las mentalidades y las relaciones de género, las ocupaciones de la gente, la vida económica, la arquitectura y el arte, la existencia de ciertas vías de comunicación no demasiado organizadas, una presencia importante del bandidaje, incluso el tipo de música y los instrumentos, etc, y también, por supuesto, la tecnología presente, reflejada sobre todo en la forma de combatir en la guerra y las armas que se utilizan (espadas, escudos, lanzas, arcos y flechas, armaduras... y más pesadas, como catapultas, escorpiones, arietes, trabucos... sin estar aún presente la pólvora) -y dejando a un lado el carácter mágico que puedan tener algunas de esas armas, en la vertiente de ambientación fantástica del juego-. La ambientación de este conocido juego de rol tal y como fue diseñado habría sido imposible sin echar mano de las fuentes históricas. Y aun siendo una ambientación medieval-fantástica, es evidente que con este juego se puede aprender bastante sobre esos aspectos generales de la vida y las culturas de la Edad Media que hemos mencionado de forma tan breve en estas pocas líneas, esto es, conocer buena parte -quizás incluso la más importante- de lo que es la historia medieval, dejando de lado esa otra concepción de la historia como mera sucesión y relato de hechos históricos, que denominaremos más bien crónicas. Los buenos conocedores de la Dragonlance, una larga serie de novelas basadas en este juego de rol, rememorarán en este momento la imagen del cronista Astinus de Palanthas para entender aquello a lo que nos estamos refiriendo como "crónicas" en lugar de la verdadera "historia", al igual que este personaje de ficción era un cronista, que recoge los hechos acontecidos, y no un historiador, que debe conocerlos pero que además, los interpreta.

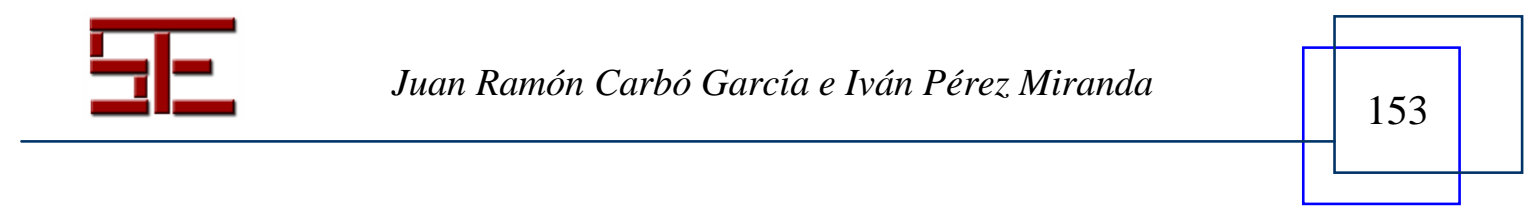




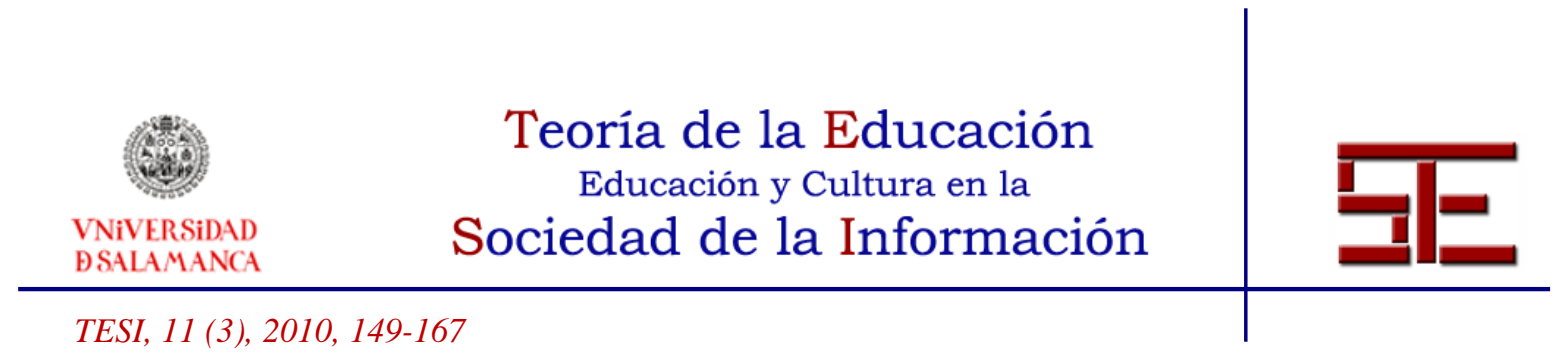

E incluso en la parte de ambientación fantástica del juego también se han usado fuentes de carácter histórico, especialmente en lo que se refiere a la mitología histórica, y no sólo la clásica, sino también otras, como la nórdica, la china o la americana precolombina: dragones, grifos, unicornios, pegasos, minotauros, enanos, elfos, trolls, gnomos, gigantes, ogros, árboles animados, etc. Y aparte de las criaturas, también se observa la influencia de las fuentes históricas en la concepción de los panteones religiosos: dioses del bien, dioses sanadores, dios neutral de la justicia, dios o dioses del mal, quizás un dios supremo, la existencia del Caos como un dios primigenio..., todos ellos tomados en su estructura y caracterización de los dioses de los diferentes panteones de las religiones antiguas. Aquí se observa una contradicción histórica, y es que la religión típica de la época medieval histórica -o al menos, de la Edad Media europea, que es la presente generalmente en éste y otros juegos-- era monoteísta, ya fuera cristiana o musulmana, y no resultaba válida para la ambientación de estos juegos de ambientación medieval-fantástica por el importante papel que en ellos juega la magia y porque precisamente las prácticas mágicas reales eran perseguidas por las religiones monoteístas y también por otros sistemas religiosos organizados (incluso politeístas, como la religión cívica romana), porque atentaban contra el control directo sobre los fieles ejercido por la religión y por el poder al que de forma habitual iba siempre unida ${ }^{1}$. De modo que los juegos echan mano sobre todo de sistemas religiosos politeístas, más propios de la Antiguiedad, sin un clero excesivamente organizado o poderoso, de modo que la magia pueda campar a sus anchas.

Esta situación se muestra muy bien, por ejemplo, en la saga de la Dragonlance, cuando los sacerdotes seguidores del dios del bien, Paladine, y su sumo sacerdote persiguen el mal con la convicción de poder erradicarlo, lo que supondría la eliminación de los dioses del mal e incluso de los neutrales, y la instalación de un sistema monoteísta con un solo clero realmente poderoso, que además muestra a las claras su aversión por la magia de cualquier tipo. Para dar continuidad a la saga, defender el politeísmo, acabar con un único clero poderoso y, por consiguiente, dar vía libre a la magia y sus prácticas, que caracterizan este tipo de juegos de rol de fantasía medieval, los dioses provocan un Cataclismo -de evidentes matices bíblicos o más generalmente de la mitología de los pueblos semitas y del medio oriente antiguo- que acaba con esa situación ${ }^{2}$. Incluso en

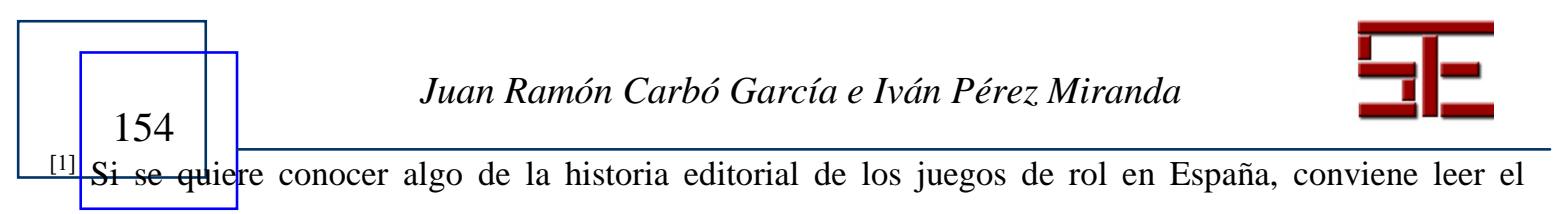




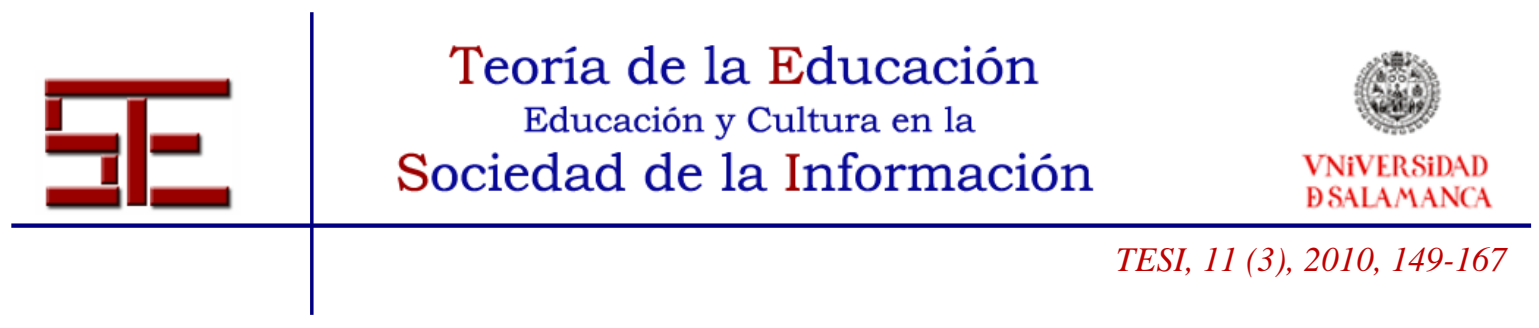

esa concepción de la religión, de los sistemas religiosos y de la magia, puede observarse con claridad la importancia de la historia, en este caso, de la historia de las religiones.

Lo que venimos diciendo sobre Dungeons \& Dragons podría aplicarse por lo general a otros juegos de ambientación medieval-fantástica, como sucedería con El Señor de los Anillos. Bien es cierto que las concepciones para este juego de rol salen de la novela principal y la producción literaria aneja de J. R. R. Tolkien (Tolkien, 1954, 1977), pero para el caso, al derivar después en un juego de rol también muy conocido y jugado, se mantiene la importancia de las fuentes históricas en su ambientación. No vamos a repetir todo lo dicho ya sobre vida cotidiana, el mundo medieval, los dioses y las concepciones religiosas, las criaturas, la magia, etc., igualmente válido en este caso, pero podemos detectar al menos algunos otros aspectos importantes del mundo de $E l$ Señor de los Anillos en relación con la historia y sus fuentes para la ambientación creada por Tolkien y desarrollada después por los equipos diseñadores del juego de rol y sus innumerables manuales y guías. Por un lado, las distintas civilizaciones humanas presentadas en El Señor de los Anillos, con la historia necesaria para sus respectivas caracterizaciones, están adaptadas a las regiones y a sus climas tal y como sucedía en la época medieval: como ejemplos, los dunedain corresponden grosso modo a la civilización medieval europea; la civilización de los rohirrim presenta unas características en su cultura, arquitectura, vida cotidiana, rasgos étnicos y capacidad combativa que les hace semejantes a los nórdicos vikingos, si bien el carácter náutico de estos últimos es sustituido por el carácter ecuestre, que les aproxima quizás a los godos de los siglos III y IV d.C.; los corsarios de Umbar (a pesar de cómo están representados en las películas) podrían evocar, por los rasgos más orientales de su civilización y su poderío naval, a Bizancio; los haradrim están caracterizados como árabes, e incluso los sureños del lejano Harad aparecen más bien como indios de la India, procedentes de lejanas regiones de fabulosas riquezas, y combatiendo como lo hacían aquéllos, con elefantes de guerra -los mumak u olifantes del Señor de los Anillos-; los variags de Khand son tártaros; los orientales aparecen caracterizados como precisamente eso, orientales chinos o mongoles, etc.

Todo lo cual está relacionado con una transposición geográfica-histórica del mundo real en el que vivió Tolkien, centrado en Europa, al mundo por él imaginado, Arda, centrado en la Tierra Media. Con ciertas salvedades importantes, la participación de Tolkien en la Primera Guerra Mundial y su pensamiento político en torno a la Segunda Guerra Mundial influyeron en la concepción de ese mundo imaginario. No hay más que seguir la historia de estas guerras para darnos cuenta de que Morgoth/Melkor y Sauron, con sus fuerzas, representan en distintas épocas al "enemigo", simbolizan "el mal", como fueron caracterizados en su momento los imperios centrales, aliados con los orientales

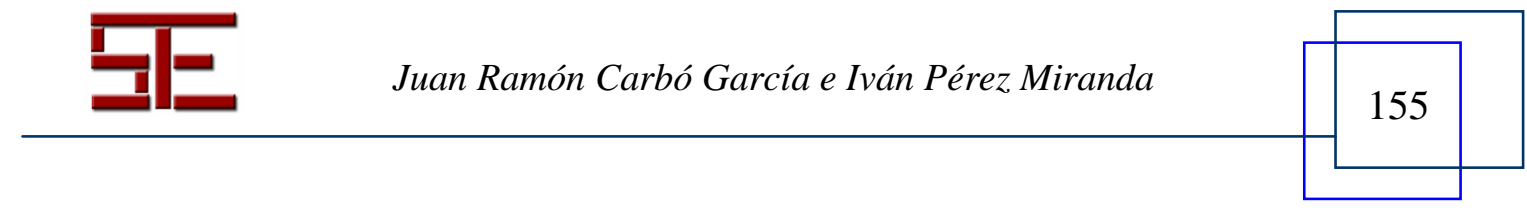




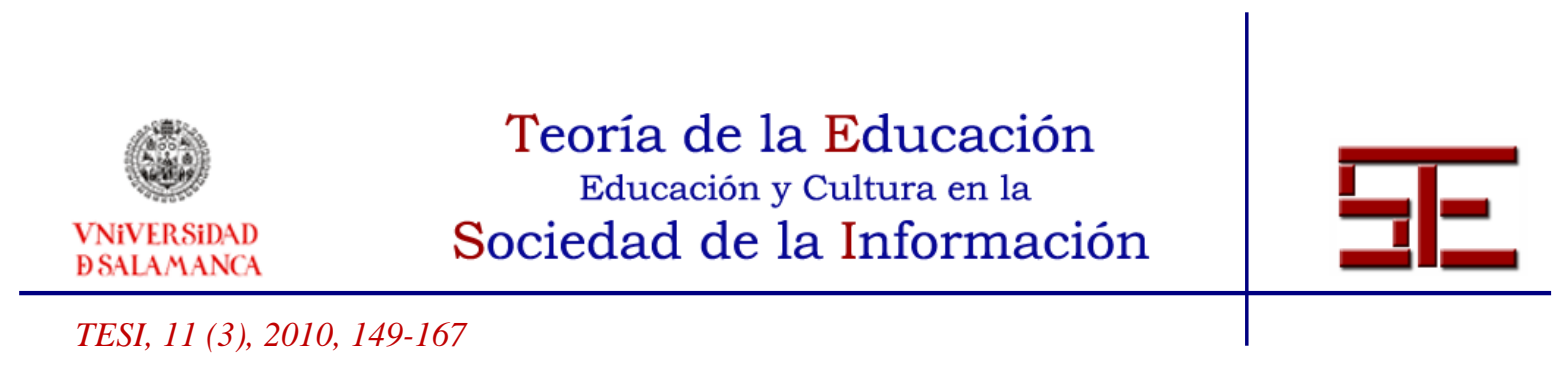

otomanos, al perder la Primera Guerra Mundial, o los nazis en la Segunda Guerra Mundial, aliados con los orientales japoneses. Los pueblos libres de la Tierra Media representan a las diferentes naciones europeas que se enfrentan a esos enemigos; y, evidentemente, las Tierras Imperecederas, situadas al oeste del Gran Mar (con un diseño geográfico muy semejante al del continente americano), y el poder de los valar, los dioses del bien, ajenos generalmente a las luchas del común de los mortales, representan a los Estados Unidos de América, que decidieron la Primera Guerra Mundial con su intervención en Europa -y también la Segunda, aunque Tolkien no repite el argumento, posiblemente entre otras cosas porque él participó en la Primera y fue entonces cuando se vio impresionado y se mostró agradecido por la ayuda estadounidense ${ }^{3}$.

Por último, el hundimiento de Númenor, la gran isla-continente existente entre Arda y la Tierra Media (Tolkien, 1977), está evidentemente inspirado en el mito de la Atlántida con su hundimiento y desaparición, y, por consiguiente, en la fuente literaria histórica aunque se refiera a un mito- que suponen los escritos realizados por Platón y dedicados al mítico continente perdido ${ }^{4}$.

Parece que vamos viendo que la historia influye, mucho más de lo que podíamos pensar en un principio, en los juegos de rol, en su ambientación e incluso en hechos históricos que son trasladados -con las evidentes variaciones necesarias- a los acontecimientos que suceden en esos juegos.

Pero vamos a plantear una situación de mayor complejidad. Dejemos los juegos de ambiente medieval-fantástico y pasemos, por ejemplo, a la ciencia-ficción: La Guerra de las Galaxias, un juego de rol inspirado, en este caso, en una saga cinematográfica. ¿Qué influencias de la historia, de fuentes históricas, podemos encontrar aquí? Algún lector podría argüir que en realidad sucede todo lo contrario, y que es La Guerra de las Galaxias la que ha influido en la historia, o al menos, en nuestro mundo contemporáneo, recordando el nombre por el que fue conocida popularmente la Iniciativa de Defensa Estratégica establecida por el presidente estadounidense Ronald Reagan, en los años 80: La Guerra de las Galaxias (Palomares-Lerma, 1994). Pero sí que podemos observar ciertas influencias: para empezar, en los Jedi. En la concepción de estos caballeros, que siguen una filosofía-religión en torno a la Fuerza en su vertiente del bien, han influido muchas filosofías y pensamientos religiosos históricos. Con

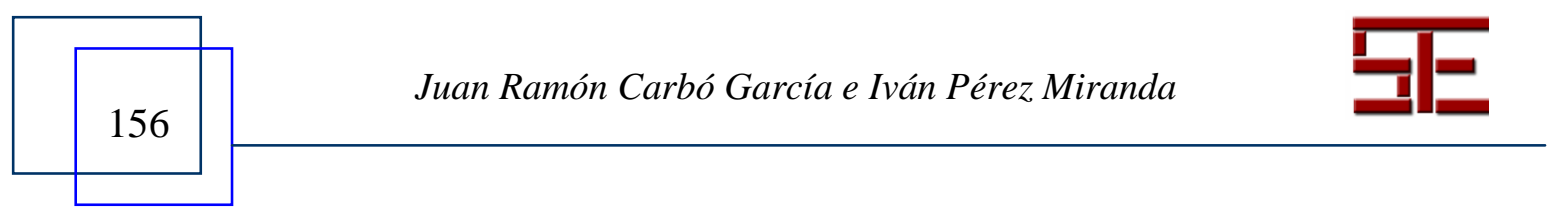




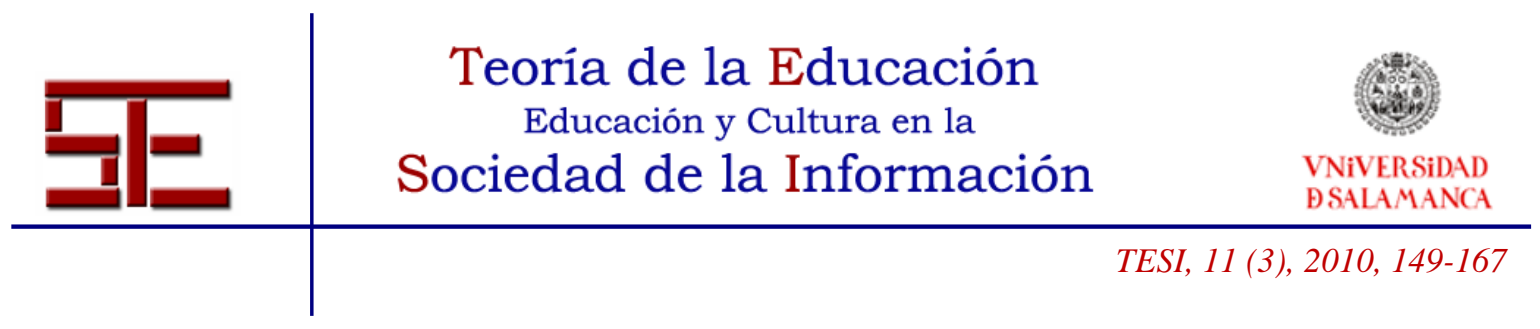

ninguno de ellos se identifican completamente, pero entre sus rasgos principales podemos observar la meditación de estilo oriental y algunas filosofías orientales (de marcado carácter histórico, aunque existan en la actualidad), y, desde luego, su carácter de orden religiosa guerrera, que les asemeja a las órdenes religiosas guerreras cristianas de época medieval como los Templarios, Hospitalarios o Teutónicos, o también a los monjes guerreros orientales.

También se observa una fuerte influencia de los sistemas políticos históricos en la concepción de los "villanos", el Imperio Galáctico, inspirado tanto en su modo de actuación, en su política y también en su imagen visual, en los sistemas políticos totalitarios históricos de corte imperialista y militarista en el siglo XX, como el nazismo de Hitler o el comunismo stalinista, de Stalin (Muñoz Pantiga, 1997). Que los nazis y la Segunda Guerra Mundial constituyeron una fuente histórica de inspiración para George Lucas, de modo que se ha transmitido de la pantalla grande al juego de rol, se demuestra por la influencia que tuvo sobre el director la obra cinematográfica de Leni Riefenstahl, actriz y cineasta alemana cuya producción propagandística en la Alemania nazi tuvo fuerte impacto: la escena final de la película La Guerra de las Galaxias está inspirada en una similar de El Triunfo de la Voluntad (1934), y los impresionantes despliegues de formaciones de tropas del ejército imperial están basados en las formaciones y desfiles de Día de la Libertad: nuestras fuerzas armadas (1935). El cine se inspiró en el cine, pero en el caso de la obra de Riefenstahl, se trata de uno de los documentales políticopropagandísticos más efectivos jamás filmado, y se trata, evidentemente, de una fuente histórica de primera importancia para la comprensión del nazismo (Bach, 2008).

Y en fin, éstas son influencias históricas en la película que se han transmitido al juego de rol. Pero en el propio juego de rol encontramos también ejemplos del uso de fuentes históricas para la ambientación e incluso podemos hallar hechos históricos que han sido integrados como eventos para la acción del juego de La Guerra de las Galaxias. Pondremos sólo un ejemplo que sirva como ilustración de este tipo de uso de fuentes históricas en los juegos de rol: en la Guía de la Alianza Rebelde de La Guerra de las Galaxias, se presentaba un evento con el título "Ataque sobre el Cinturón de Fara" (Williams, 1996,75). Los rebeldes planean un importante ataque con cazas de última generación sobre una base imperial, a la que dan el nombre en código "Estrella subterránea". Sin que lo supieran, los servicios de Inteligencia imperiales habían descifrado el código rebelde y estaban escuchando las transmisiones del sector, y supieron que una base imperial sería atacada en breve, pero aunque conocían el ataque en el sector, no sabían cuál de sus muchas bases en él era esa "Estrella subterránea". La Inteligencia imperial desarrolló un plan para hacer que los rebeldes se descubrieran ellos mismos. Los imperiales ordenaron que cada una de las bases incluyera en sus informes

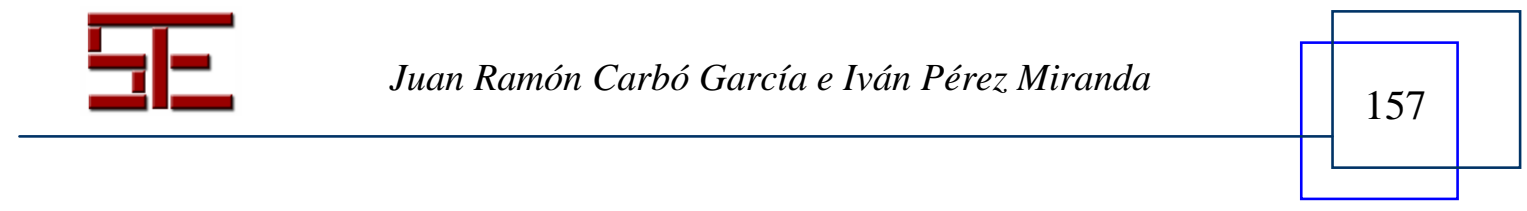




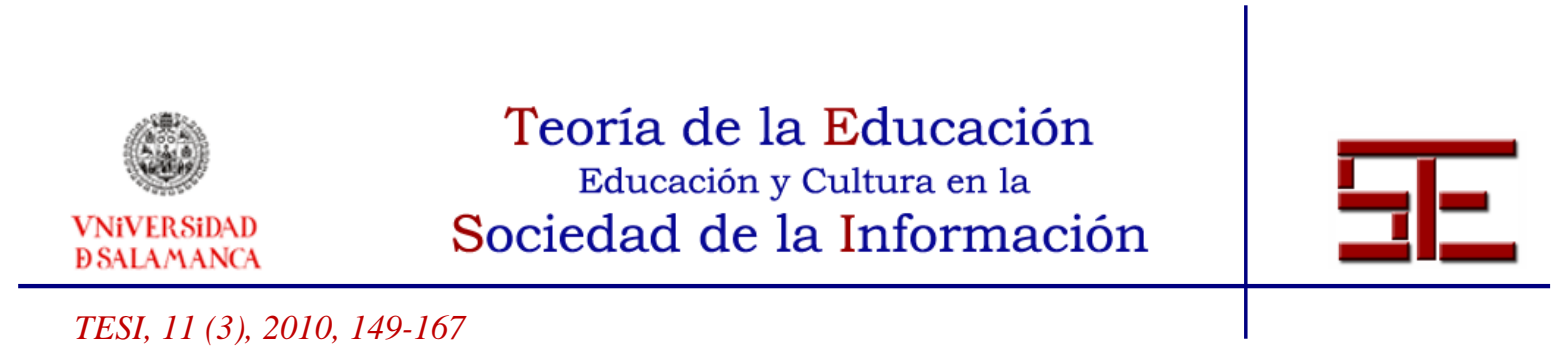

al Cuartel General una comunicación sobre algún tipo de mal funcionamiento de los sistemas, y cada base debía informar de un mal funcionamiento diferente. Después, sólo tuvieron que esperar hasta que la Inteligencia imperial interceptó una transmisión rebelde que decía que la "Estrella subterránea" tenía "problemas con el suministro de energía", y en ese instante supieron que el objetivo del ataque era la base en el Cinturón de Fara. Cuando las fuerzas rebeldes aparecieron, fueron aplastadas por una fuerza imperial que sabía que llegaban.

Pues bien, este evento es una copia exacta, sólo con las variaciones debidas a la adaptación de ambiente en el espacio, de lo que ocurrió en junio de 1942, durante la Segunda Guerra Mundial, en los prolegómenos de lo que sería la batalla de Midway: los estadounidenses interceptaron una transmisión japonesa y con la argucia señalada, y refiriéndose al depurador de agua de la base, el capitán de fragata Joseph Rochefort consiguió averiguar que el objetivo japonés, cifrado como AF, era Midway. Allí los estadounidenses esperaron a los japoneses, les vencieron y pusieron en fuga, y entonces cambió el signo de la guerra en el Pacífico, que hasta ese momento había sido casi un paseo triunfal para las fuerzas niponas, siendo uno de los puntos de inflexión más importantes de la guerra (Barker, 1976,72).

He aquí una utilización más de fuentes históricas -esta vez de un hecho o evento de cierta importancia- para los juegos de rol. Como ya hemos señalado, la historia constituye una fuente importante para la elaboración de los juegos de rol, que se basan de un modo u otro en el mundo real, pasado o presente, para después variarlo en diferente medida dependiendo del grado de fantasía o ficción que se desee introducir en ellos -si es que se desea, por supuesto-.

Evidentemente, cuanto mayor sea el grado del carácter histórico que pueda tener un juego de rol, mayor será la importancia de las fuentes históricas para la ambientación, eventos, personajes y el desarrollo del juego en general. ¿Y qué sucede, tal y como planteábamos al comienzo de nuestra intervención, con la fantasía histórica? Vamos a recordarlo: por fantasía histórica queremos referirnos a la elaboración de mitos y fantasías que llegan a formar parte de la historia, como, por ejemplo, sucedería con la mitología. Decíamos que los mitos expresan los puntos de vista y las creencias de un país, una época, una cultura o una religión que constituyeron su origen. Cuando en un juego de rol de fantasía histórica aparece, por ejemplo, un dios o un héroe mítico griego, o tal vez el minotauro de Creta, o un centauro, o unas ninfas... como en el juego Oráculo, o sin necesidad de retrotraernos al mundo clásico, aparecen personajes de leyendas y mitos populares, como en el juego Aquelarre, es evidente que al instante queda reducido el carácter "realista", pero de ninguna manera se reduce la importancia de las fuentes históricas para ese juego, ya que estamos hablando de mitología y son las

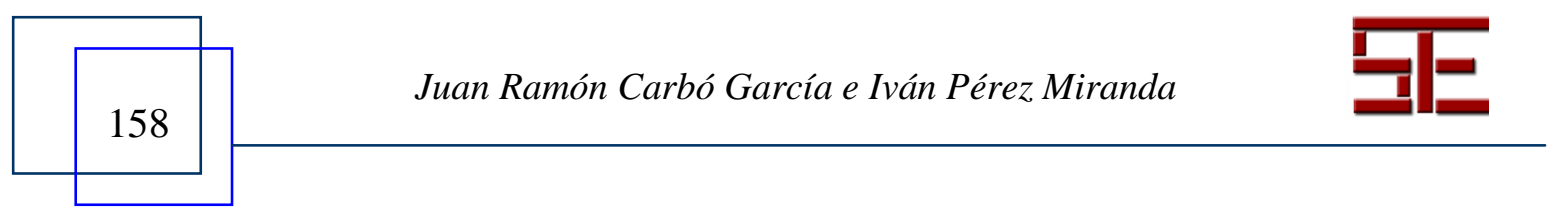




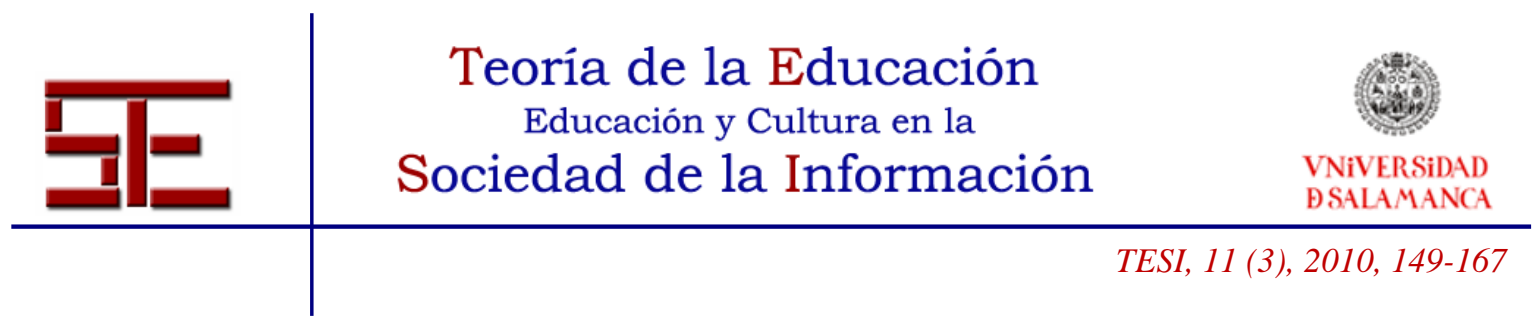

fuentes históricas las que nos informan, las que nos proporcionan los datos necesarios, acerca de esos mitos que aparecen en ellas y que son introducidos en el juego, proporcionando si se desea ese ambiente fantástico, pero sin renunciar a un carácter más histórico como sucede con la mera fantasía, si bien ya hemos visto que ésta también tiene lazos relevantes con las fuentes históricas. Lo que sucede es que al jugar a esos juegos de fantasía histórica, la sensación de realidad no puede ser igual que si se juega, por ejemplo, a Comandos de guerra, ambientado con enorme realismo en la Segunda Guerra Mundial, o a Las aventuras del Capitán Alatriste, ambientado en la España del siglo XVII, pero debemos reiterar que la fuerte importancia de las fuentes históricas para unos y otros no varía apenas.

Mencionábamos el juego Oráculo como uno de los pocos de tipo histórico -aunque éste es más bien de fantasía histórica- ambientados en la Edad Antigua que han sido publicados en nuestro país. La reciente tesis del Dr. Sevillano puede ilustrarnos más sobre esta cuestión en relación con la edición de juegos de rol en España (Sevillano Pareja, 2008), y dando ya paso a la parte final de nuestra intervención, referida a aspectos didácticos de los juegos de rol para el caso específico de la Historia Antigua, podemos constatar que son muy pocos los casos de juegos de rol ambientados en la Antigüedad de los que podemos disponer en lengua española y que hayan sido publicados, de modo que la solución más habitual ha sido diseñarlos a modo de soluciones "caseras", que en algunos casos han sido colgados en la Red para su libre descarga y uso.

Entre ellos, cabría mencionar Hispania Fudge, de Jon Perojo Gutiérrez y Ana Rodríguez González, ambientado en las guerras púnicas y las guerras de conquista de Hispania por los romanos, desde finales del siglo III al I a.C.; también ambientado en la Península Ibérica estaría Hispania. Terra indomita Germanicorum, de Blas Malo Poyatos, pero ya en la época visigoda; otro juego, Mazes \& Minotaurs -Laberintos y minotauros-, de Legendary Games Studio, sigue el mismo planteamiento de Oráculo en cuanto a su concepción como juego de fantasía histórica, ambientado en la Grecia de los dioses, héroes y criaturas mitológicas; más histórico es Alejandro Magno, de Rittman, cuya presentación es reveladora: "El juego de rol para jugar la historia", y no hace falta decir más sobre su ambientación histórica; y, por supuesto, el que vamos a comentar como juego usado en el experimento didáctico del que hablábamos al principio de nuestra intervención, S.P.Q.R. -Senatus Populusque Romani-, de Juan Ramón Carbó, ambientado en la época alto-imperial romana.

Este experimento ha sido desarrollado entre 2002 y 2008, y en él han participado varios doctores, licenciados y alumnos de diferentes facultades de la Universidad de Salamanca, y, por consiguiente, con diversos niveles de conocimiento de la Historia

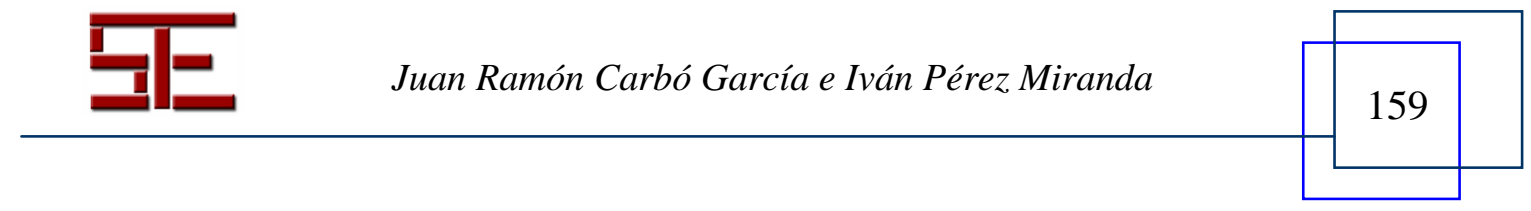




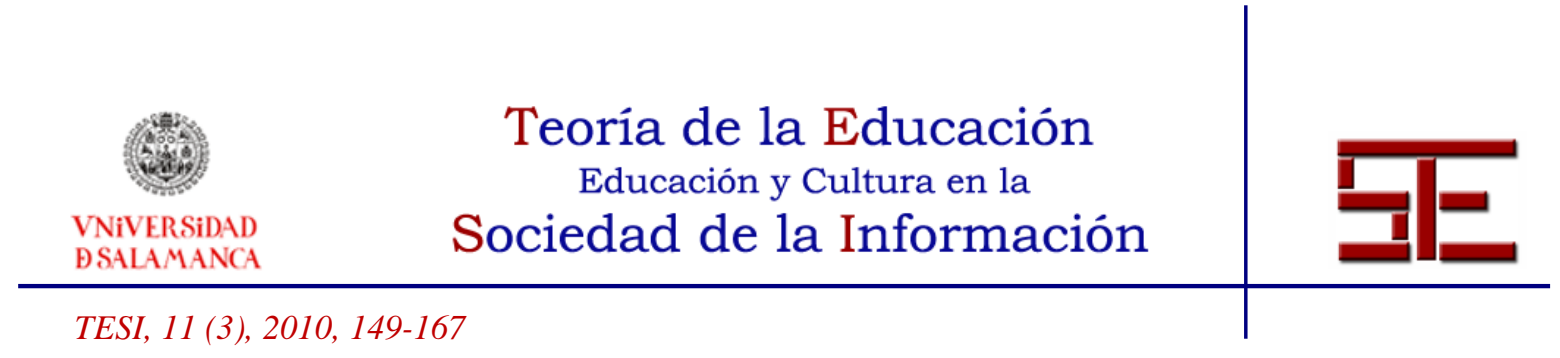

Antigua y de formación histórica en general. Los planteamientos, la motivación y los resultados obtenidos, que vamos a exponer brevemente para dar término a nuestra exposición, pueden suponer un jarro de agua fresca para la renovación de los métodos tradicionales de enseñanza y el aprendizaje de la Historia Antigua -y, por comparación, también en otras disciplinas históricas-. Precisamente queremos mostrar este experimento como una propuesta didáctica en unos momentos en los que al habitual clamor contra las clases más o menos "magistrales", contra los apuntes y contra los exámenes como formas principales utilizadas para la transmisión y valoración del conocimiento en las carreras universitarias, se suma además la inminente implantación de los nuevos planes de estudio -no menos protestados, aunque ahora no vamos a entrar en esa cuestión-- y el establecimiento de un método diferente para la enseñanza, transmisión del conocimiento y valoración del aprendizaje obtenido por los alumnos, que estaría basado en mayor medida en la tutela directa de un profesor sobre varios alumnos, en las lecturas y comentarios de libros y artículos y en la realización de seminarios. ¿En qué medida podrían los juegos de rol históricos, como S.P.Q.R. o cualquiera de los mencionados, ser introducidos y utilizados como método de enseñanza y de aprendizaje adicionales en ese nuevo sistema, en algunos de esos seminarios o en parte de esas tutorías, en lo que respecta al nuevo Grado de Historia?

Uno de los objetivos principales era comprobar la viabilidad de usar un juego de rol de temática histórica y ambientado en época antigua durante un tiempo mínimo de la duración de una asignatura relacionada, y un tiempo máximo de los años de duración del grado, a expensas del interés demostrado por los participantes. El otro objetivo primordial, evidentemente, era valorar el grado de construcción del conocimiento alcanzado por los participantes, que habían comenzado el juego con un diferente nivel de conocimientos previos sobre el tema.

Entre los participantes había un doctor en Historia Antigua -ejerciendo como director-, un licenciado con grado en Historia Antigua, una licenciada con grado en Historia Medieval, un licenciado en Historia, un alumno de la carrera de Historia, una licenciada en Historia del Arte, un doctor en Física Nuclear, un alumno de Física, un licenciado en Informática y también un oficial de las Fuerzas Armadas españolas.

La época general elegida para el juego fue la del Alto Imperio romano, y con más precisión se eligió la época de los emperadores Flavios (69-96 d.C.) ${ }^{5}$. Los jugadores tuvieron que interpretar durante las diferentes partidas a personajes de distinta índole:

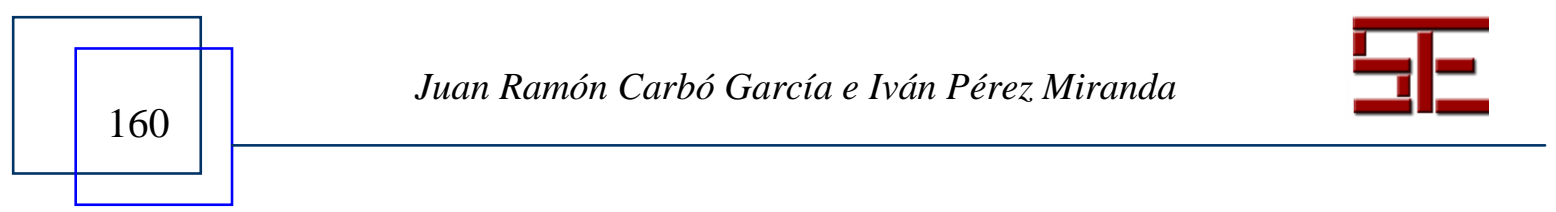




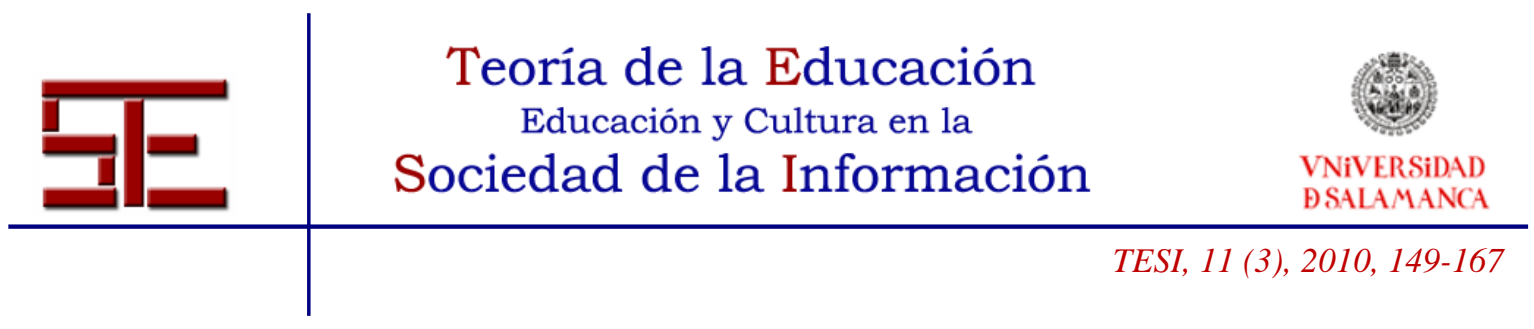

dos hijos de senadores enfrentados políticamente, y dos hijos de ecuestres, en su avance por el cursus honorum; una noble romana, con algún grado de parentesco con dos de los anteriores; un centurión de las cohortes urbanas en Roma; un suboficial galo-romano con tendencias rebeldes -es la época del levantamiento de Julio Civilis en la Galia- ${ }^{6}$; un filósofo epicúreo griego de tendencias homosexuales; una princesa bretona de los brigantes, tomada como rehén en Roma; y un mercenario celta y gladiador libre.

Los escenarios en los que se desarrollaron las diferentes partidas del juego fueron Roma - con la inmensa cantidad de posibilidades que ofrece--; Ostia y la zona del Lacio; la zona de la Campania en torno a Capri, Sorrento, Herculano, Pompeya y el Vesubio, coincidiendo con la erupción del volcán en el año 79; Córcega; la Galia; y finalmente Britania, coincidiendo en el tiempo con las campañas de conquista y sometimiento de los brigantes efectuadas por Cneo Julio Agrícola (Tácito, 1988).

Entre las situaciones abordadas podríamos mencionar los diversos aspectos de la vida cotidiana en Roma, en las casas, calles, mercados, templos, termas, tabernas, teatros y otros edificios de espectáculos; la sociedad, las clases y el cosmopolitismo de la urbs; la carrera política y militar y el funcionamiento de las instituciones; las ideologías, el poder imperial y el funcionamiento de la burocracia; la religión y las creencias; la mitología - tratada sólo como creencia, sin introducir elementos fantásticos en el juego-; las carreras en el Circo Máximo y los espectáculos de gladiadores y de fieras en la inauguración del Coliseo o Anfiteatro Flavio; la organización de la seguridad urbana; el ejército y la flota romanas, y la guerra; los pueblos bárbaros sometidos y los libres, y sus perspectivas respecto a los romanos; las vías de comunicación y los viajes por tierra y por mar; el mencionado evento de la erupción del Vesubio; y un largo etcétera.

Y se introdujeron personajes históricos no jugadores con los que tuvieron que interactuar los jugadores: los emperadores Vespasiano, Tito y Domiciano, los cónsules y generales Cerealis, Frontino y Agrícola, escritores como Plinio el Viejo y Plinio el Joven, Tácito y Suetonio, y otros de menor entidad cuyos nombres y personalidades nos han llegado gracias a las obras de los propios historiadores romanos Suetonio y Tácito (Suetonio, 1992; Tácito, 1988, 2006).

Durante todo el tiempo y las diferentes partidas que duró el juego, los participantes se implicaron en mayor o menor medida, pero a la vista de los resultados, es indudable que todos ellos, desde los que tenían más conocimientos previos de la época hasta los que no tenían prácticamente ninguno, mejoraron significativamente sus conocimientos

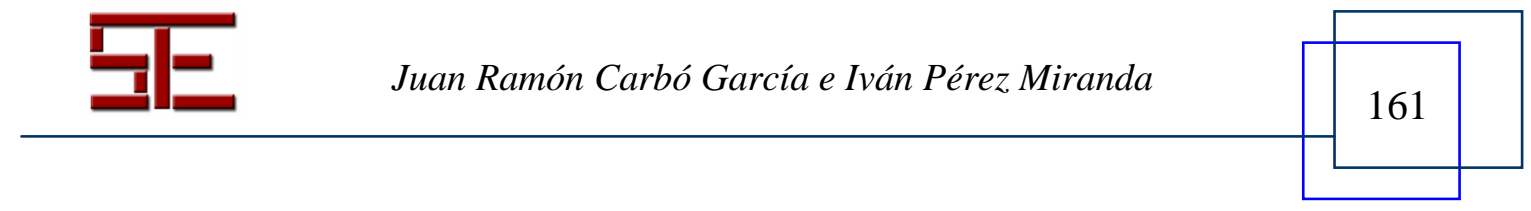




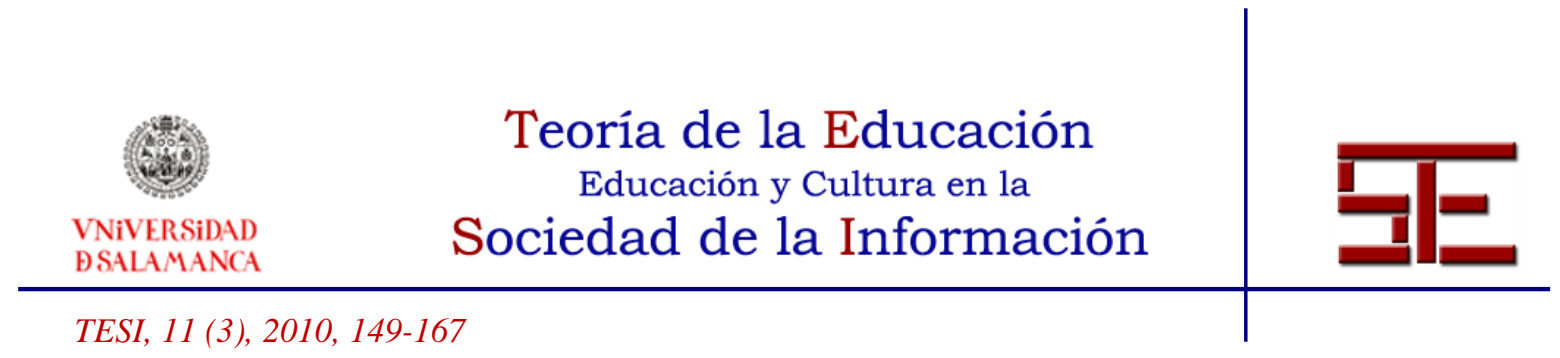

conceptuales, pero también pudieron observarse cambios procedimentales y actitudinales muy positivos, en la búsqueda y consulta de fuentes para caracterizar, darle un fondo realista e interpretar mejor a sus personajes, y también en la construcción cognitiva conjunta, en el trabajo en equipo y en la evaluación cognitiva igualmente conjunta. Si lo que se pretendía era realizar un aprendizaje por inmersión en el que los participantes pudieran interactuar con el objeto de aprendizaje, el juego de rol, los resultados fueron muy satisfactorios para todos los participantes, a lo que hay que añadir el importantísimo aspecto lúdico: el aprendizaje divertido -divertido no tiene por qué chocar con un propósito serio y responsable- resulta mucho más productivo.

El juego de rol, al presentar un amplio abanico de posibilidades de interacción entre los personajes y en los diferentes escenarios planteados, resultó muy propicio para generar el entorno de aprendizaje que pretendíamos experimentar, y que puede ponerse en práctica con unos sujetos protagonistas -los alumnos- que van a aprender por inmersión y deben además tomar decisiones que resulten de argumentaciones fundamentadas y negociadas. Y más allá de los contenidos específicos, el modo en que se manejen las interacciones en los diferentes escenarios y los grados de libertad de los personajes interpretados por los jugadores/alumnos son los que van a determinar las características del juego. Los juegos de rol dan la posibilidad a los estudiantes de elaborar, ir construyendo, probar e incluso evaluar conjuntamente sus conocimientos y habilidades, mediante la interacción con personajes virtuales y la consulta de una gran variedad de recursos, de fuentes históricas, en suma, para lograr los objetivos planteados en el juego (Vacca; Bonelli; Pioli, 2008, 8-9).

Desde el punto de vista educativo, el aspecto lúdico de los juegos de rol supone un incontestable motivador para todos los participantes en él, esto es, los alumnos, pero también para el profesor o tutor -no lo olvidemos-. Y además de esa vertiente lúdicoacadémica, los juegos de interpretación presentan una gran utilidad para incidir en las ideas de tolerancia y de empatía. Al situar a los alumnos en situaciones imaginarias, pero basadas en la historia, podremos hacerles experimentar las sensaciones y los pensamientos de otras personas - de personas de otros tiempos históricos o incluso de personajes históricos conocidos- en los diversos escenarios de la historia planteados, reforzando esa vertiente empática. Los alumnos-jugadores se verán en la situación de tener que convivir y cooperar con personas de otras culturas y razas, y evidentemente es muy posible que ellos mismos se encuentren en la tesitura de tener que interpretar a un personaje de una raza o cultura diferente a la suya, de tal modo que si la guía es correcta, los juegos de rol aplicados a la historia pueden muy útiles para el aprendizaje de comportamientos socialmente positivos y estimulantes, basados en el conocimiento

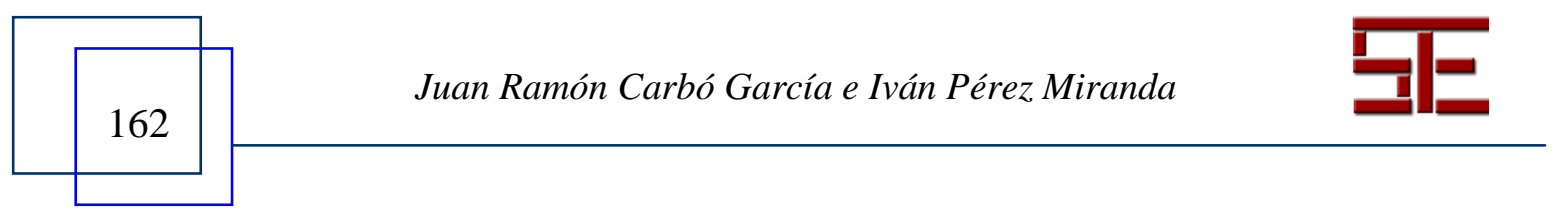




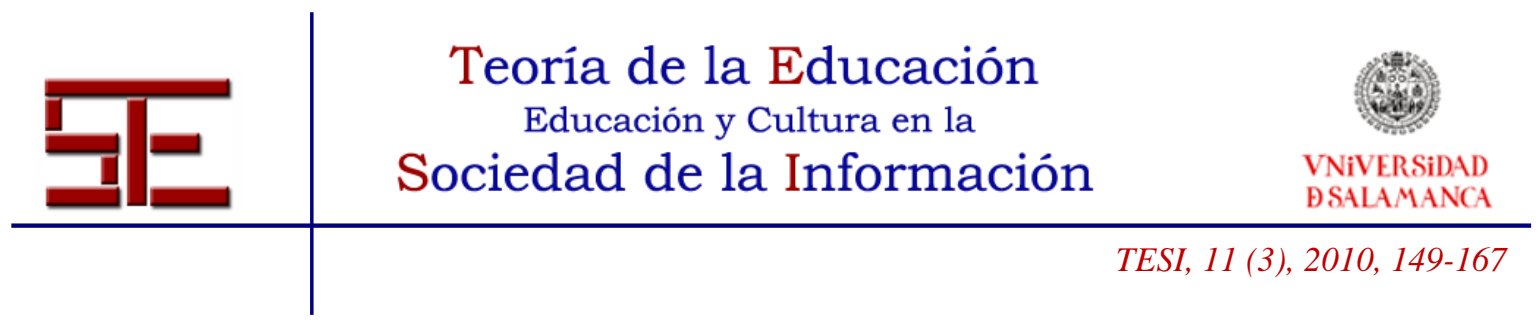

de otras culturas históricas diferentes y de comportamientos sociales del pasado distintos de los nuestros (Vedovelli Orán, 2002,7).

Para plantear y ambientar el tema y la acción que se pretende recrear, el director del juego (el profesor o tutor) debe ayudarse de diversas fuentes históricas que traten de esos temas y al mismo tiempo debe proporcionar a los alumnos/jugadores una lista de esas mismas u otras fuentes históricas. De esa forma, se ayuda a los alumnos a familiarizarse con la consulta de manuales generales, monografías, artículos y fuentes clásicas, para encender en ellos -con la motivación que supone el aspecto lúdico del juego-- el ansia de investigar otras fuentes, no proporcionadas a priori, donde poder aprender más sobre la época en la que se desarrolla la partida y que les ayuden a interpretar mejor sus personajes y a conocer más el medio y a los otros personajes que les rodean. Y un aspecto interesante más de los juegos de rol es que su propia vertiente lúdica afecta de igual manera al profesor o tutor que dirige las partidas: puede haber excepciones, pero lo normal es que al director no le apetezca dirigir una y otra vez la misma partida con diferentes grupos -es decir, mismo escenario, mismo planteamiento, misma acción y mismos personajes no jugadores, al margen de que los nuevos alumnos jugadores puedan interpretar a los mismos o a otros personajes nuevos-. El director puede aburrirse, de modo que el aspecto lúdico del juego le motiva para ir cambiando los escenarios, planteamientos, acciones y personajes de las partidas, lo que tiene como consecuencia que tenga que prepararlas y se esfuerce más en buscar y consultar fuentes históricas para los nuevos temas: por consiguiente, renovación e incluso ampliación de su conocimiento y de sus propias capacidades de aprendizaje. Así pues, los juegos de rol presentan unas ventajas educativas importantes, pero no sólo para los alumnos, sino también para los profesores, contribuyendo a evitar el "anquilosamiento" cognitivo al que, por ejemplo, conducen de forma casi inevitable los temas preparados para las habituales clases "magistrales" de una asignatura, repetida año tras año para diferentes cursos y alumnos, dándose casos en los que tal repetición llega a rozar el pie de la letra. Con el "aprendizaje por inmersión integral" que se consigue con el juego de rol concebido éste como "objeto de aprendizaje"- se construye el conocimiento en colaboración, trascendiendo la tradicional transmisión-recepción de contenidos. Y en lo que se refiere a la evaluación, se tendrán en cuenta la coherencia de las intervenciones de cada participante, con los rasgos de identidad de su personaje; la calidad de las fuentes documentales y el apoyo fundamentado en ellas para las intervenciones durante el juego; y la calidad de la colaboración en la construcción del conocimiento, la evolución de las habilidades cognitivas que se pretendían desarrollar con el juego de rol, y los cambios conceptuales, procedimentales y actitudinales logrados (Vacca; Bonelli; Pioli, 2008,4-9). Y esa evaluación trascenderá igualmente el modo tradicional,

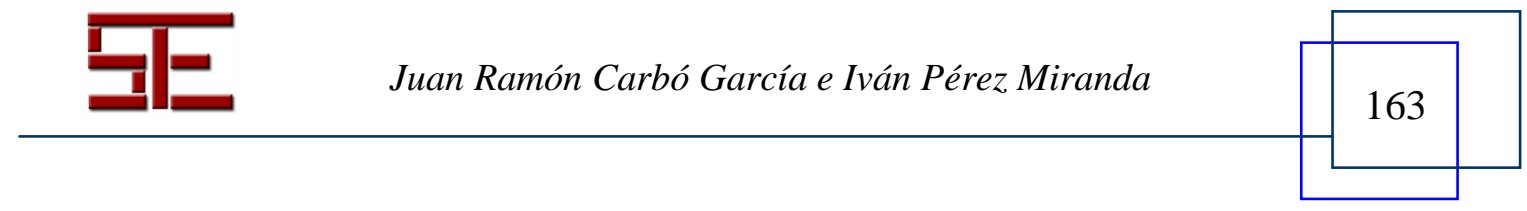




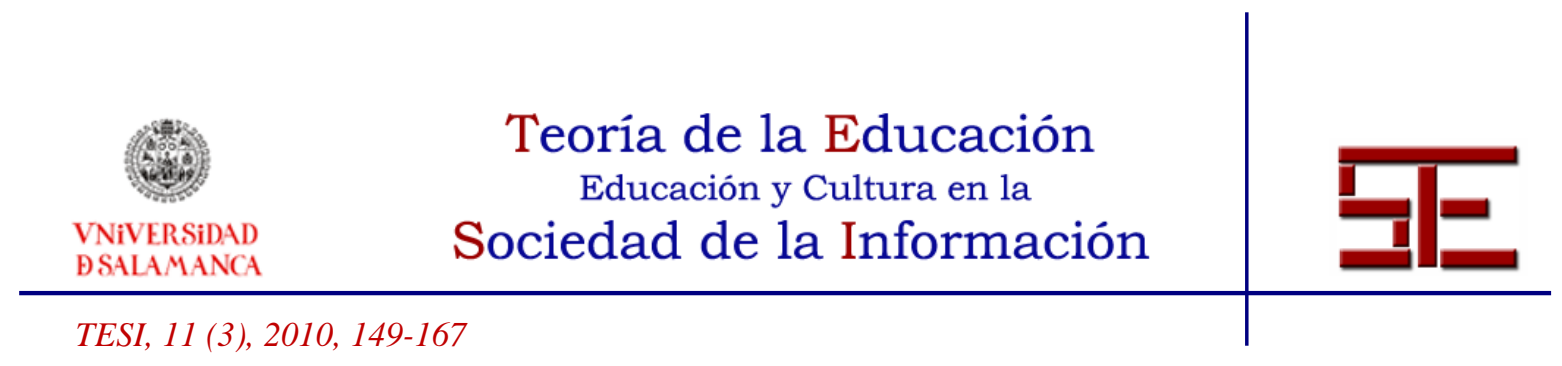

considerándose las opiniones auto-evaluadoras de los alumnos participantes, evaluadoras de éstos sobre los demás, y del profesor-tutor sobre cada uno, dependiendo de los criterios señalados anteriormente. Si la construcción cognitiva se potencia y se realiza en colaboración, lo natural es que la evaluación de esa construcción también se realice en colaboración, en lugar de la típica evaluación personal del profesor respecto a cada alumno: los criterios señalados pueden ser evaluados por todos los alumnos participantes desde el primer día hasta el último, porque habrán tenido que demostrarlos en cada partida, y si no lo han hecho, no tendrán argumentos para defender delante de sus compañeros y del profesor una nota más alta en su propia evaluación, que en cualquier caso el profesor puede decidir ponderar en función de los conocimientos previos del alumno.

Somos conscientes de que puede parecer una utopía o, al menos, presentar algunos aspectos fácilmente considerados como utópicos, sabemos que los juegos de rol no son la panacea y desde luego no proponemos que vengan a sustituir el modo de enseñanza tradicional. Sin embargo, al menos podrían ser tenidos en cuenta como un método didáctico adicional y complementario que puede ser usado en parte del tiempo completo destinado a una asignatura, como en algunos de los seminarios o tutorías mencionados, o como complemento de los trabajos de investigación que deban realizar los alumnos en la asignatura.

Concluyendo ya, hemos podido comprobar que la historia constituye una fuente de relevancia para la elaboración de los juegos de rol, basados en mayor o menor medida en el mundo real --pasado o presente- para después variarlo en diferente grado dependiendo del nivel de fantasía o ficción que se puede desear introducir en ellos. Y cuanto mayor sea el nivel del carácter histórico del juego de rol en cuestión, mayor será la importancia de las fuentes históricas para ese juego, y, al mismo tiempo, mayor será su utilidad didáctica para la enseñanza de la historia, como método a tener en cuenta para contribuir al logro de implantar una nueva modalidad de aprendizaje en la Universidad, más allá incluso del empleo de los juegos de rol en actividades extraordinarias en la enseñanza secundaria, donde sin ser habituales todavía como método didáctico complementario, sí pueden ser detectados, al contrario de lo que ocurre por lo general en las enseñanzas superiores.

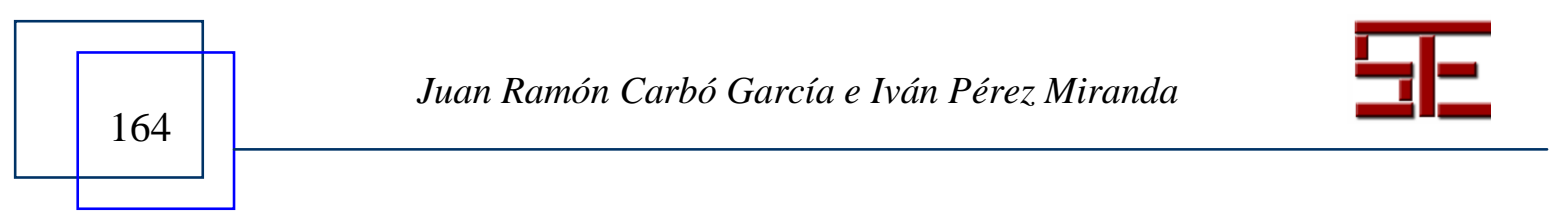




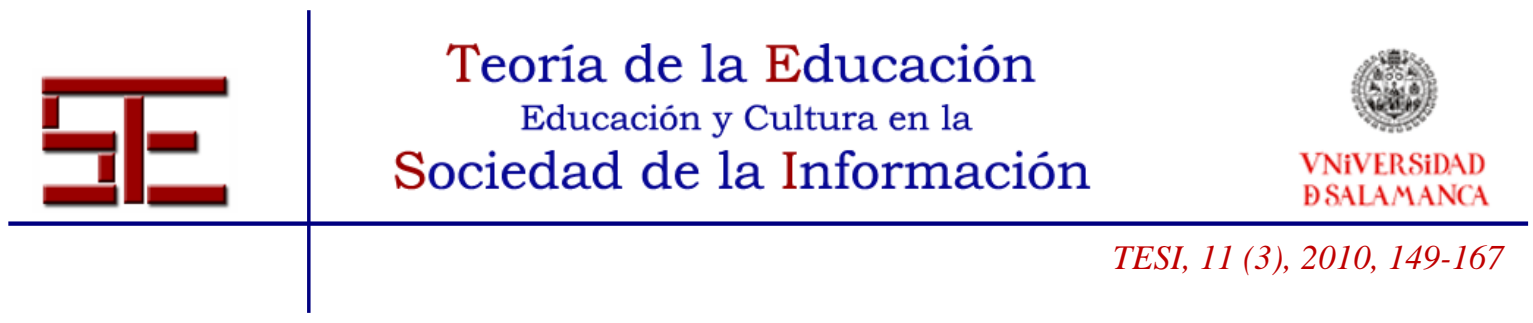

\section{BIBLIOGRAFÍA}

Bach, S. (2008). Leni Riefenstahl. Barcelona: Circe.

Barker, A. J. (1976). Midway: el momento crítico, Madrid: Librería Editorial San Martín.

Carpenter, H. (1990). J. R. R. Tolkien, una biografía. Barcelona: Minotauro.

Gordon, R. (1990). Religion in the Roman Empire: the civic compromise and its limits. En Beard, M. y North, J. (eds.), Pagan Priests. Londres: Cornell University Press, (pp. 235-255).

Jones, B. W. (1984). The Emperor Titus. Londres: Croom Helm.

Levick, B. (2005). Vespasian. Londres: Routledge.

Muñoz Pantiaga, D. (1997). Las galaxias de George Lucas. Barcelona: Glénat.

Palomares Lerma, G. (1994). La era Reagan. Madrid: Editorial Información e Historia.

Platón (2003). Diálogos. VI: Filebo. Timeo. Critias. Madrid: Gredos.

Sánchez, D. (2006-2007). Juegos de rol. Mito y realidad (Diss.), en <dreamers.com/defensadelrol/articulos/Juegos_de_rol__Mito_y_realidad.pdf > .

Scheid, J. (1991). La religión en Roma. Madrid: Ediciones Clásicas.

Sevillano Pareja, H. (2008). El sector editorial de los juegos de Rol: análisis del editor, el lector y el traductor. Tesis doctoral. Universidad de Salamanca.

Sissa, G. y Detiene, M. (1994). La vida cotidiana de los dioses griegos. Madrid: Ediciones Temas de Hoy.

Southern, P. (1997). Domitian: tragic tyrant. Londres: Routledge.

Suetonio (1992). Vida de los doce césares. Madrid: Gredos.

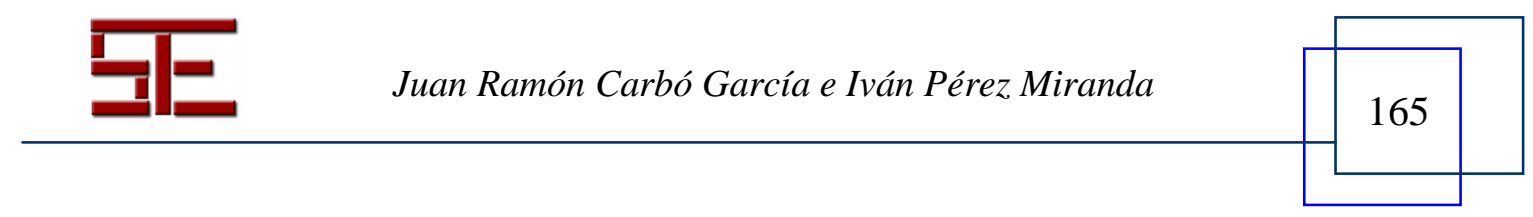




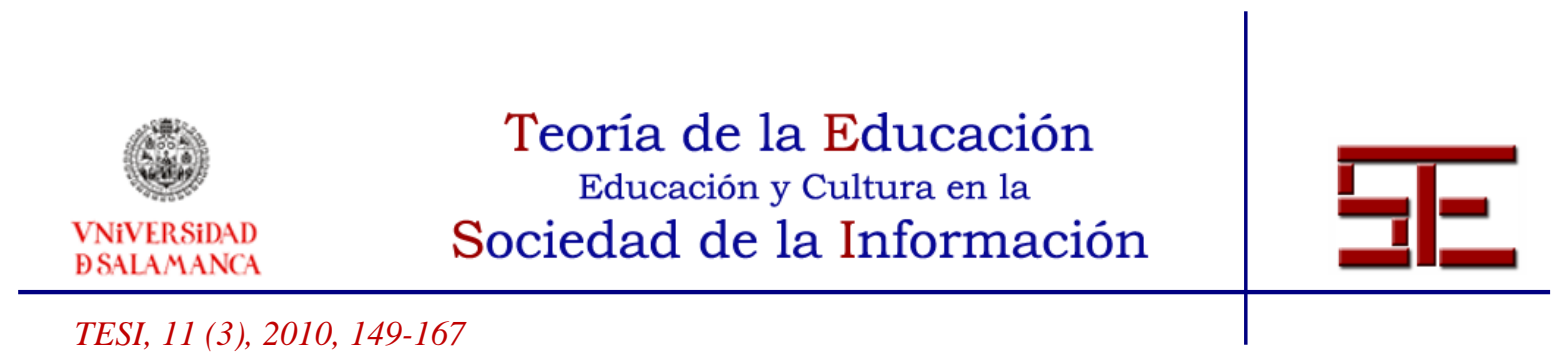

Tácito (1988): Agrícola. Madrid: Gredos.

- (2006). Historias. Madrid: Cátedra.

Tolkien, J. R. R. (1954). The Lord of the rings (Novela). Oxford: George Allen \& Unwin Ltd.

- (1977). The Silmarillion. Akallabéth (Novela). Oxford: George Allen \& Unwin Ltd.

Vacca, A. M., Bonelli, J. \& Pioli, A. (2008). Los juegos de rol como objeto de aprendizaje, en http://eljuegoderol.com/JDR/JDR_archivos/JDR_LOGIN.htm.

Vedovelli Orán, J. L. (2002). Rol para peques, o cómo iniciarse en los juegos de interpretación, en http://rolparapeques.rolgratis.com/.

Vernant, J.P. (1991). Mito y religión en la Grecia antigua. Barcelona: Ariel.

Vidal-Naquet, P. (2005). La Atlántida. Pequeña historia de un mito platónico. Madrid: Akal.

Weiss, M., \& Hckman, T. (1986). Leyendas de la Dragonlance I: El templo de Istar (Novela). Barcelona: Timun Mas.

WIilliams, J. A. (ed.) (1996). Star Wars: Guía de la Alianza Rebelde. Barcelona: West End Games - JOC Internacional.

\section{NOTAS:}

${ }^{1}$ La magia podía servir igualmente de mediación en la comunicación con la divinidad, siendo uno de los enemigos fundamentales del sistema sacrificial greco-romano, ya que según éste los magos pervertían el código sacrificial para sus propios fines malignos y eran un ejemplo del caos que resultaría de la desaparición del papel religioso del emperador, garante del orden social, político y religioso. $C f r$. Gordon (1990), 253-254.

${ }^{2}$ Estos pasajes de la saga de la Dragonlance aparecen relatados en una de las novelas centrales, de Weiss y Hickman (1986). El Templo de Istar.

${ }^{3}$ Una biografía de J. R. R. Tolkien, tratando sobre los momentos y experiencias de su vida, y los pensamientos políticos que influyeron en su obra, por Carpenter (1990).

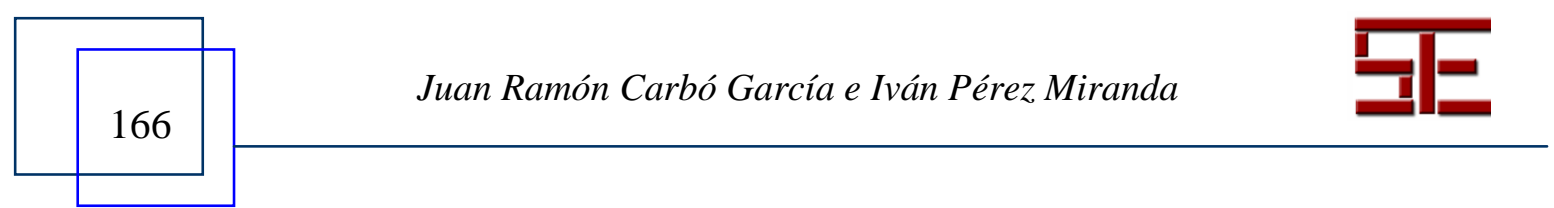




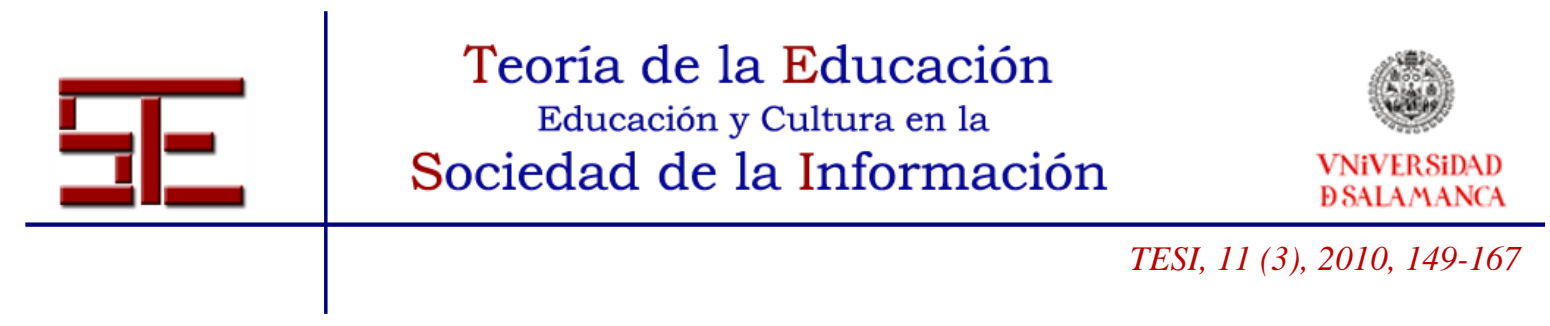

${ }^{4}$ Platón recoge el mito de la Atlántida en dos de sus diálogos, el Timeo y el Critias, remitiendo el conocimiento de la leyenda al legislador ateniense Solón, que a su vez la habría aprendido de los egipcios. Platón (2003). Sobre el mito, ver también Vidal-Naquet (2005).

${ }^{5}$ La bibliografía sobre estos emperadores es abundante, por lo que nos limitaremos a mencionar tan sólo un título relevante para cada uno de ellos: Levick (2005); Jones (1984); Southern (1997).

${ }^{6}$ Cayo Julio Civilis fue el origen y el líder de una rebelión de los bátavos, un pueblo germano de la desembocadura del Rin, contra el poder de Roma, en los años 69 y 70 d.C. Ver Tácito( 2006, 320).

Para citar el presente artículo puede utilizar la siguiente referencia:

Carbó García, J.R. y Pérez Miranda, I. (2010). Fuentes históricas de los juegos de rol: un experimento para la didáctica de la historia antigua, en Orejudo González, J.P. (Coord.) Perspectiva educativa y cultural de "juego de rol". Revista Teoría de la Educación: Educación y Cultura en la Sociedad de la Información. Vol. 11, n 3. Universidad de Salamanca, pp. 149-167 [Fecha de consulta: dd/mm/aaaa]. http://campus.usal.es/ revistas_trabajo/index.php/revistatesi/article/view/7454/7471

Juan Ramón Carbó García e Iván Pérez Miranda 